\title{
Internet of things (IoT) based traffic management \& routing solution for parking space
}

\author{
Zulnazim Dzulkurnain ${ }^{1}$, Abd Kadir Mahamad ${ }^{2}$, Sharifah Saon ${ }^{3}$, \\ Mohd Anuaruddin Ahmadon ${ }^{4}$, Shingo Yamaguchi ${ }^{5}$ \\ ${ }^{1,2,3}$ Faculty of Electrical \& Electronic, Universiti Tun Hussein Onn Malaysia, Malaysia \\ ${ }^{4,5}$ Graduate School of Science and Technology for Innovation, Yamaguchi University, Japan
}

\begin{tabular}{l} 
Article Info \\
\hline Article history: \\
Received Dec 14, 2018 \\
Revised Feb 15, 2019 \\
Accepted Mar 1, 2019 \\
\hline
\end{tabular}

\section{Keywords:}

Internet of things (IoT)

Parking solution

Routing solution

Time management

Traffic management

\begin{abstract}
The idea of Internet of Things (IoT) based traffic management \& routing solution for parking space is due to the vehicle parking has become major issue in urban areas. The growing number of vehicles has contributed to the traffic problem and vehicle parking issue nowadays. The main purpose of this project is to assist the user to locate the vacant parking space, which help to reduce time and fuel consumption on searching the parking space. This proposed system was used online system via website application, which assist people to find the available parking slot. In fact, the system counted the capacity of the available parking space and notified the user through the website application. Frankly, the system was equipped with an ultrasonic sensor, which acts as the detector that sent data to the microcontroller in order to update into UBIDOTS cloud server for data logger purposes. This system could lessen or solve the time management problem at the parking area, which user could save their time by checking the available parking slots in advance through the website application.
\end{abstract}

Copyright $\odot 2019$ Institute of Advanced Engineering and Science. All rights reserved.

\section{Corresponding Author:}

Abd Kadir Mahamad,

Faculty of Electrical \& Electronic Engineering,

Universiti Tun Hussein Onn Malaysia,

86400 Parit Raja, Batu Pahat, Johor, Malaysia.

Email: kadir@uthm.edu.my

\section{INTRODUCTION}

Traffic congestion has become an issue nowadays, that lead major cities manipulate the technology for a better, faster and productive ways to get access around [1-3]. Nobody enjoys overcrowded vehicular population, thus urban transportation has become one of the key elements for a smart city. Drastic growth of traffic population are the major cause of road congestion. However, it can be solved through proper planned road networks and intelligent traffic management strategies [2-6].

The adaption of technology would further enhance traffic flow through optimization of load carry capacity of existing roads, coupled with advanced technology and collaboration tools to enable enforcement officers to have greater awareness and accuracy which provides for better decision making [3-10].

With centralized traffic management via UBIDOTS application, the proposed system become powerful integrated data analysis and management functions, and set to become the foundation for university as a smart campus.

Motivation of this project come from several number of other related researches. Traffic delay estimation with V2X communication for an isolated intersection was designed by Salman et al. [1]. This researchers had proposed a novel approach, specially designed to estimate traffic delay with low penetration rate (PR) for an isolated intersection. The proposed work applied fuzzy logic system by estimating the arrival and departure patterns for each incoming edge. A vehicular communication providing 
the average speed to estimate the arrival and leaving time which then used to determine the delay for each incoming edge with suitable adaption mechanism. The proposed approach is realized and evaluated using COLOMBO framework. The result from the simulation determine the approach proposed can be used for traffic delay estimation with good accuracy even under low PR [1].

In the era of industrial revolution 4.0, merging existing and new technology with the Internet of Things (IoT) system, offer the beneficial impact. Thus, real-time smart traffic management system for smart cities by IoT and Big Data provide better service by deploying traffic indicators to update the traffic details instantly [2, 8-9]. Application of low-cost vehicle detecting sensors which is embed in the middle of the road for every 500 meters or 1000 meters for data collection are cost effective. In order to acquire traffic data, the IoT are being used, which have been deployed and been processed through IoT system. Meanwhile, for realtime streaming data been sent for Big Data analytics [11, 12].

Yavari et al [4], focus on the development of IoT based smart services for solving urban problems that involve IoT; enabled Observation, Orientation, Decision, and Action (OODA) loops. Besides, the author also focus on IoT supports Observation via the discovery of sensors and the integration of the data [4], which also supports Orientation to include only those that are relevant to the situation and/or activities of each specific individual or group. At the same time, the related approach and techniques for performing internet-scale data contextualization have been proposed.

\section{RESEARCH METHOD}

Development of this real-time vehicle counter is divided into four phases; which are, Phase 1: vehicle counting algorithm development, Phase 2: integration of coding into Wemos D1, Phase 3: design real-time monitoring HTML webpage and Phase 4: the integration of data gained on UBIDOTS to HTML webpage. Figure 1 shows the flowchart of proposed method.

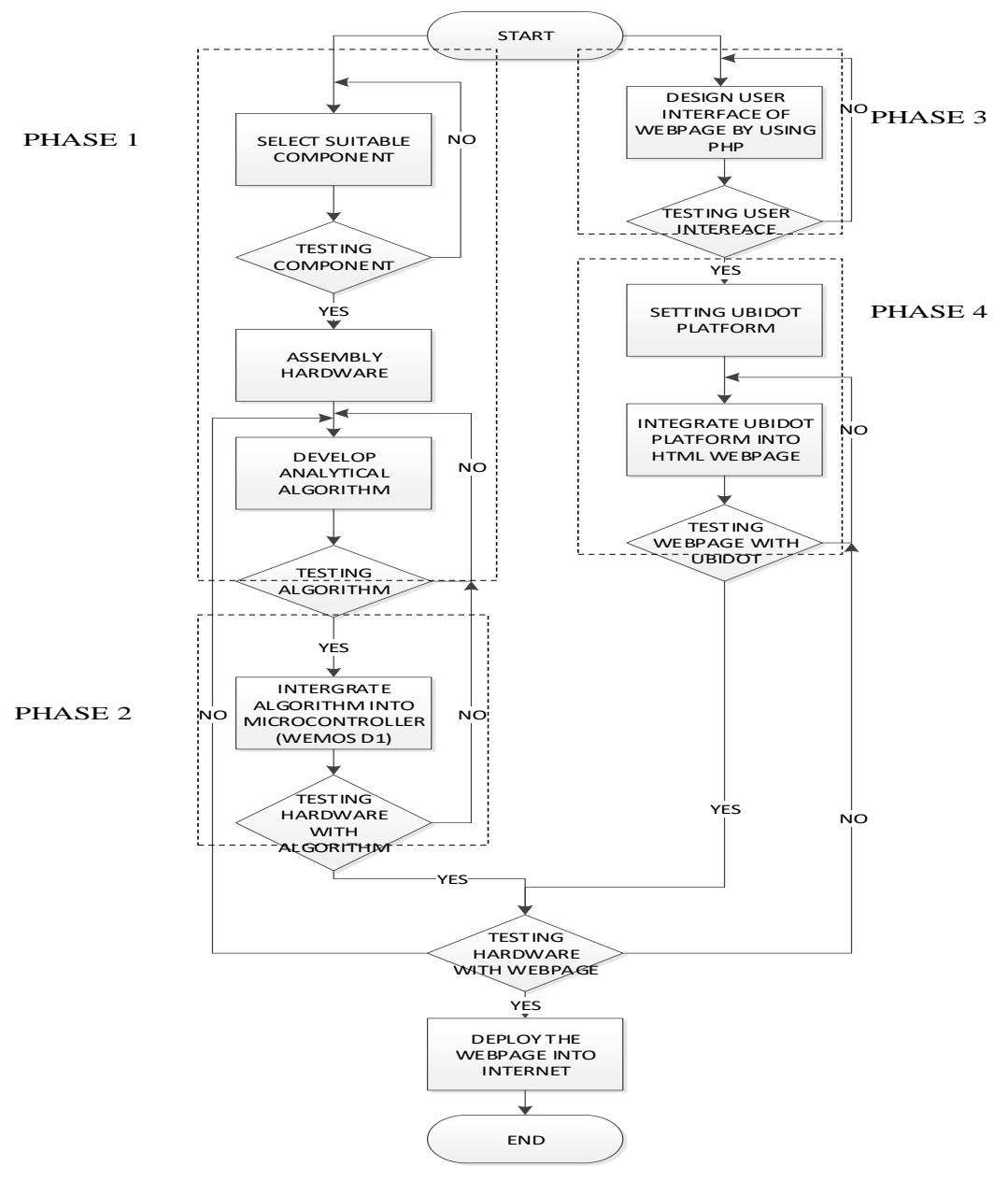

Figure 1. Flowchart of proposed method 


\section{Phase I: Development of vehicle counting algorithm}

An analytical algorithm was developed by using $\mathrm{C}++$ language to monitor and analyze the vehicle pattern and their movement passing the sensor. In order to develop the algorithm, the sensor need to be calibrate for the suitable distance. This is to ensure the sensor is in working condition for the proof the concept (PoC).

To accomplish the algorithm development, the process includes the nested "if else" for the condition to count the vehicle. It is important part of the algorithm to declare whether the vehicle passing the sensor is car or other vehicles. For this project the main purpose is to count vehicle so the algorithm must be suitable to count the vehicles.

\section{Phase II: Development of vehicle counting algorithm}

To develop a traffic management system, the developed algorithm was integrated with the Wemos D1. The vehicle-counting algorithm was deployed on Wemos D1 for analysis of the incoming and outgoing vehicle that gather from the distance sensor. Distance sensor was connected through Wi-Fi connection using Wi-Fi module.

Figure 2 shows the block diagram of Wemos D1. There are several models of Wemos D1. The Wemos D1 used in this project was Wemos D1 prototyping kit. This model was powered by 3.3V/2A and has a 32-bit RISC microprocessor core based on the Tensilica Xtensa Diamond Standard 106 Micro and running at $80 \mathrm{MHz}$. It has a faster processor compared to Arduino. Besides that, this model comes with Wi-Fi module on board. In this project, Wi-Fi availability is important as the system can be accessed remotely for convenience in configuration process.

$\begin{array}{lll}\text { Pin } & \text { Function } & \text { ESP-8266 Pin } \\ \text { D0 } & \text { RX } & \text { GPIO3 } \\ \text { D1 } & \text { TX } & \text { GPIO1 } \\ \text { D2 } & \text { IO } & \text { GPIO16 } \\ \text { D3(D15) } & \text { IO,SCL } & \text { GPIO5 } \\ \text { D4(D14) } & \text { IO,SDA } & \text { GPIO4 } \\ \text { D5(D13) } & \text { IO,SCK } & \text { GPIO14 } \\ \text { D6(D12) } & \text { IO,MISO } & \text { GPIO12 } \\ \text { D7(D11) IO,MOSI } & \text { GPIO13 } \\ \text { D8 } & \text { IO,Pull-up } & \text { GPIO0 } \\ \text { D9 } & \text { IO,pull-up, BUILTIN_LED GPIO2 } \\ \text { D10 } & \text { IO,pull-down,SS } & \text { GPIO15 } \\ \text { A0 } & \text { Analog Input } & \text { A0 }\end{array}$

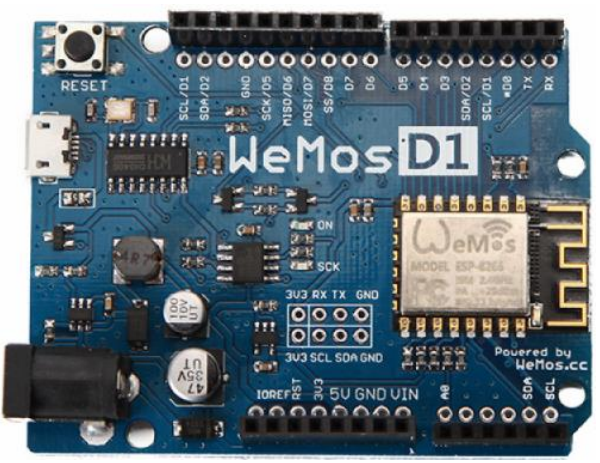

Figure 2. Wemos D1 board

\section{Phase III: Design a real-time monitoring HTML webpage}

To ensure the successful of this phase, Notepad++ have be installed into the laptop that was going to be used for the further process in this project. Notepad++ is used to design a webpage application using HTML language. When the default setting was successfully build, then the development process is in the right track. The HTML language was used widely for webpage development. In order to design the webpage in HTML, specific programing required to be done.

Lastly, after the design was ready, the webpage application was deploy on a web host. The web host that have been use was the "000webhosting" page.

\section{Phase IV: Integration of data gained on UBIDOTS}

The developed algorithm then have be tested based on its functionality. Once, the algorithm was successfully developed, the data have been shared on the cloud medium, UBIDOTS. A UBIDOTS dashboard was created to ensure the data can be shared and accessed by others. The data was integrated into the realtime monitoring webpage application and the system performance have been evaluated.

In the second part of the project which uses webpage application for real-time monitoring, the data shared on UBIDOTS which was integrated using developed webpage application and being host by "000webhost". Lastly, the system performance was evaluated on its functionality whether the result obtained was as expected. 


\section{RESULTS AND ANALYSIS}

In this section, result of this project have been discussed. In order to analysis the current performance of the Traffic Management \& Routing Solution using ESP8266 with UBIDOTS, s everal experiments had been carried out regarding the accurateness and effectiveness. The type of sensor have been used was the infrared sensor (SHARP GP2Y0A21YK) in order to detect the object, analyze the functionality of the system. This system was created through software development, and focusing on the number of vehicle entering parking lot, that shown through the UBIDOTS dashboard.

\subsection{Hardware Development}

Figure 3 shows the connection had been made to develop the circuit of the system. It shows that the infrared sensor (SHARP GP2Y0A21YK) was connected to Wemos D1 board. The systems was operated once the sensors detect an object in front of it, thus the program can be executed. The algorithm was classified whether the detected object were motorcycles, vehicle or another object by counting time from the point the sensor start detecting the object. If the object was vehicle, the counter status sent the data to UBIDOTS cloud.

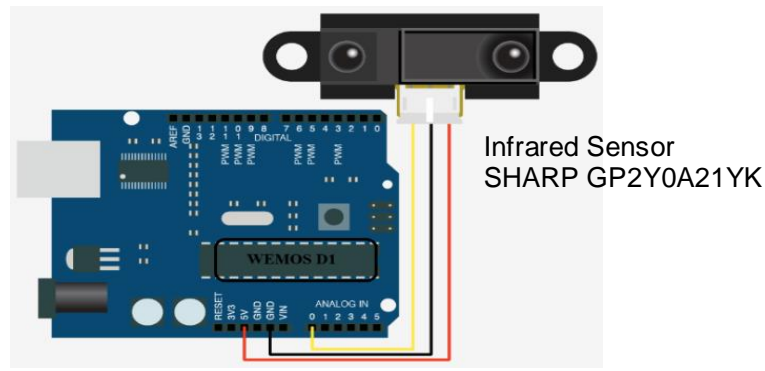

Figure 3. The circuit connection of the overall system

From the datasheet, the minimum distance that can be detected by sensor was more than $10 \mathrm{~cm}$ and the maximum was $80 \mathrm{~cm}$. For out of range distance, the sensor were unable to detect the object. Figure 4 shows the experimental setup to determine the operation of the sensor, which should be able to detect the object within the range as specified. The reason to use this kind of sensor was to proof of concept (PoC) before it can be change to suitable sensor for industries purposes. The outcome of this experiment is shown as in Table 1.

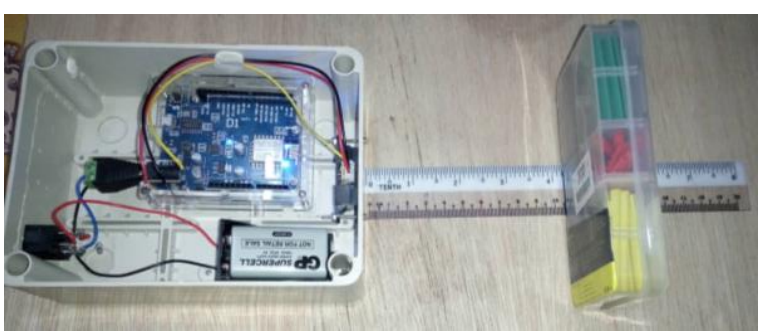

Figure 4. The experiment to test the sensor
Table 1. Result of the Experiment

\begin{tabular}{cc}
\hline Distance $($ in cm) & Sensor detect (YES or NO) \\
\hline 0 & NO \\
5 & NO \\
10 & YES \\
15 & YES \\
20 & YES \\
25 & YES \\
30 & YES \\
40 & YES \\
50 & YES \\
60 & YES \\
70 & YES \\
75 & YES \\
78 & NO \\
80 & NO \\
\hline
\end{tabular}

Once the sensor meets the condition that have been setup it have been update the cloud to match the number of current condition. When the vehicle was in entering lane, the system was count the time. If it meet the requirement, it decrease by one and sent the remaining value to the UBIDOT cloud, which decrease the number of available parking space. Figure 5 shows the graph on UBIDOT dashboard. The Y-axis shows the number of available parking space while the $\mathrm{X}$-axis shows time and date. As can be seen, the total number of vehicle at the current time is as in blue circle was updated from time to time. 
The same goes to the vehicle at outgoing lane, when it meet the requirement the increase counting status was sent the value to UBIDOT cloud in order to update the current situation, thus the number of available parking space have been increased. The graph for outgoing have been update as same as shown in Figure 5.

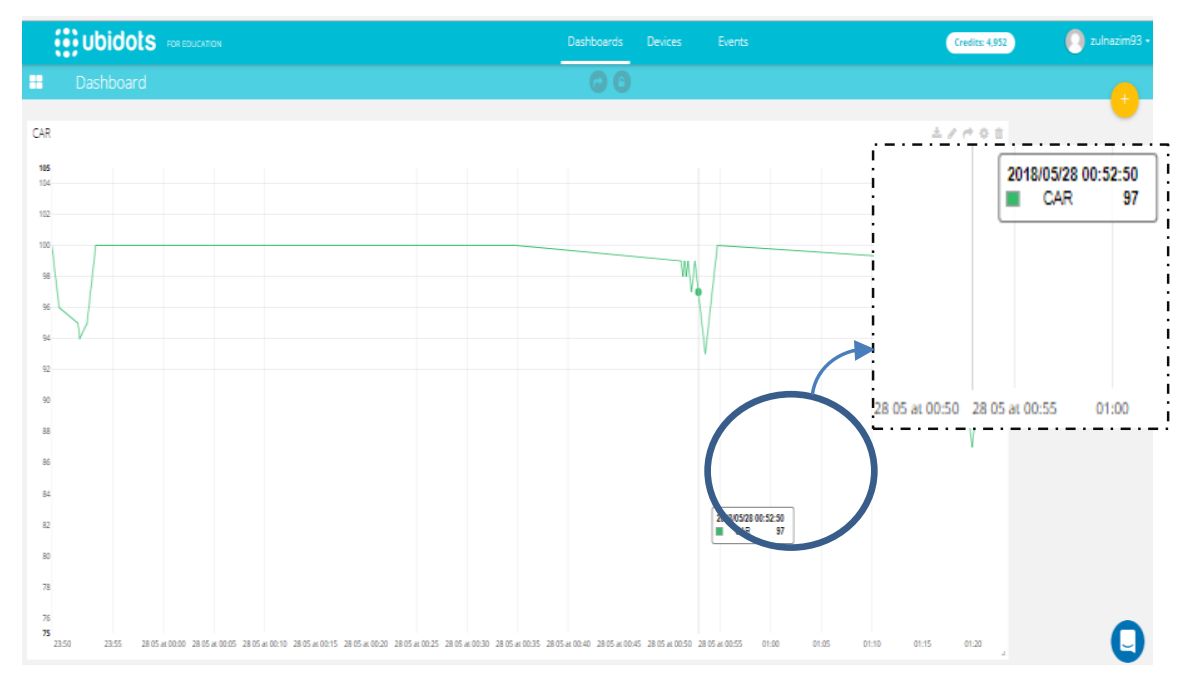

Figure 5. Vehicle status on the UBIDOTS dashboard

\subsection{Software Development}

Figure 6 shows the algorithm to suit the requirement for this project. The algorithm has a several parts, which were connect to internet, the algorithm and the data that need to be send to UBIDOTS cloud.

This coding had been programmed into the Wemos D1 in order to develop and operate the system using infrared sensor and communicate to the cloud. The coding includes the operation of the sensor that was detected the object which count the time from the sensor begin to detect object until reach the requirement. Thus, any increase or decrease the number of the vehicle was based on distance. Besides, the coding also includes the requirement of the transmitted data to the UBIDOT in order to calculate total number of the vehicles.

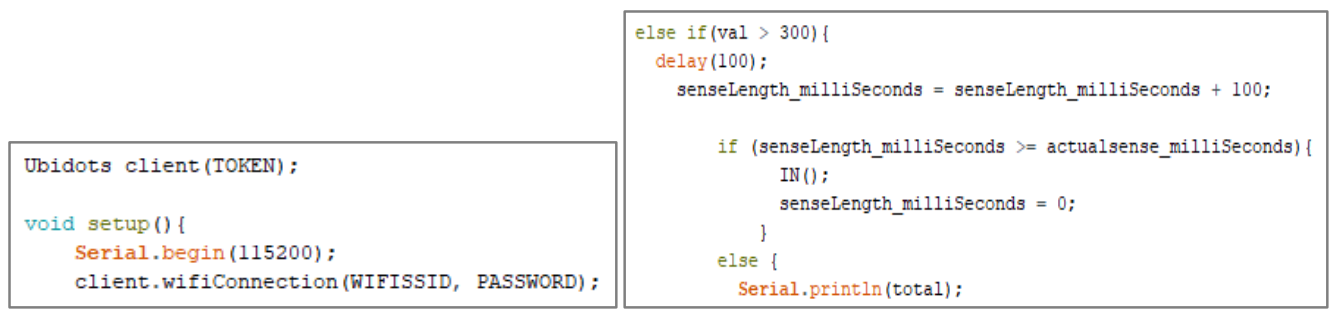

(a)

(b)

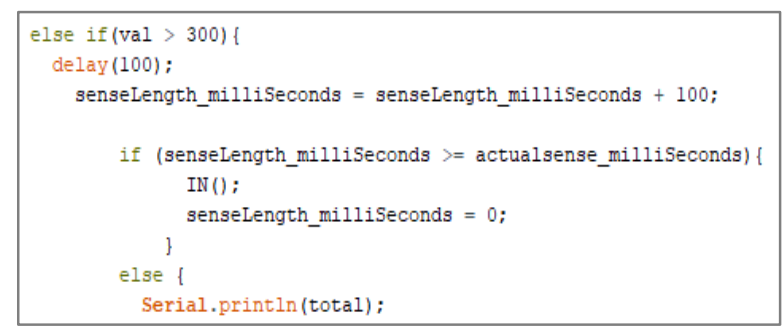

(c)

Figure 6. The program for algorithm in Wemos, (a) Wi-Fi connection, (b) incoming vehicle sensing and counting \& (c) outgoing vehicle sensing and counting 


\subsection{Webpage Development Result}

For webpage development, the webpage was developed in HTML language. The webpage was contained three main part which were the Homepage, About Writer and Data Logging page. Figure 7 show the coding of webpage development. The webpage also connected to UBIDOT cloud to get the data and display it on the webpage.

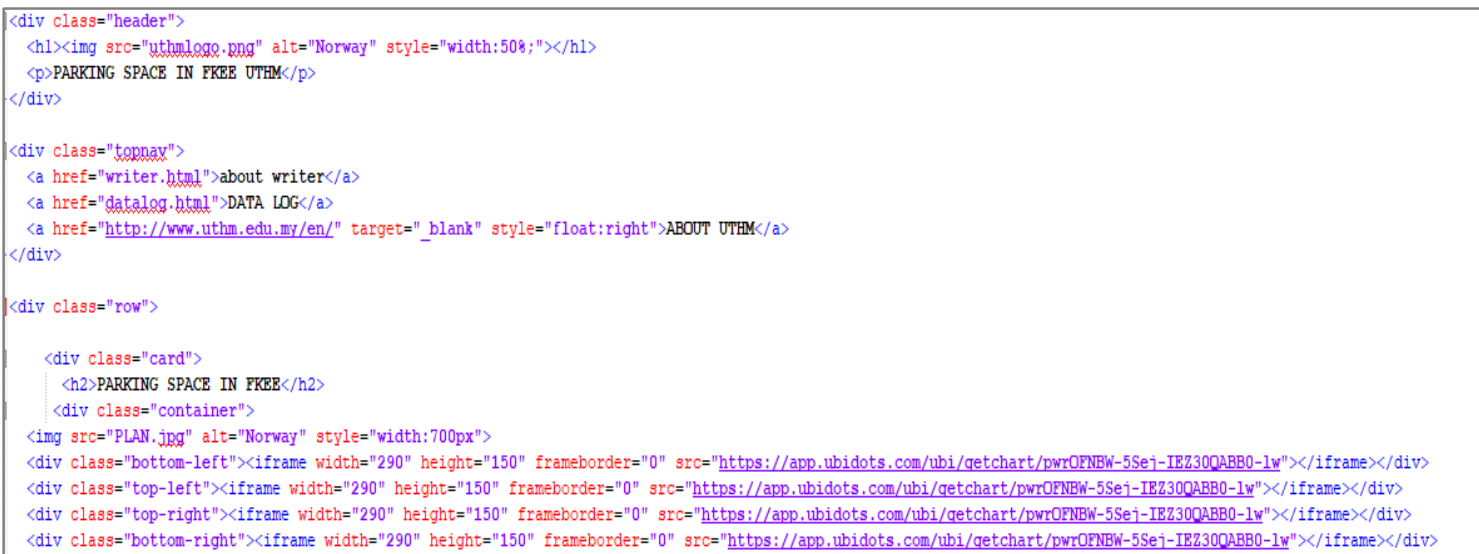

(a)

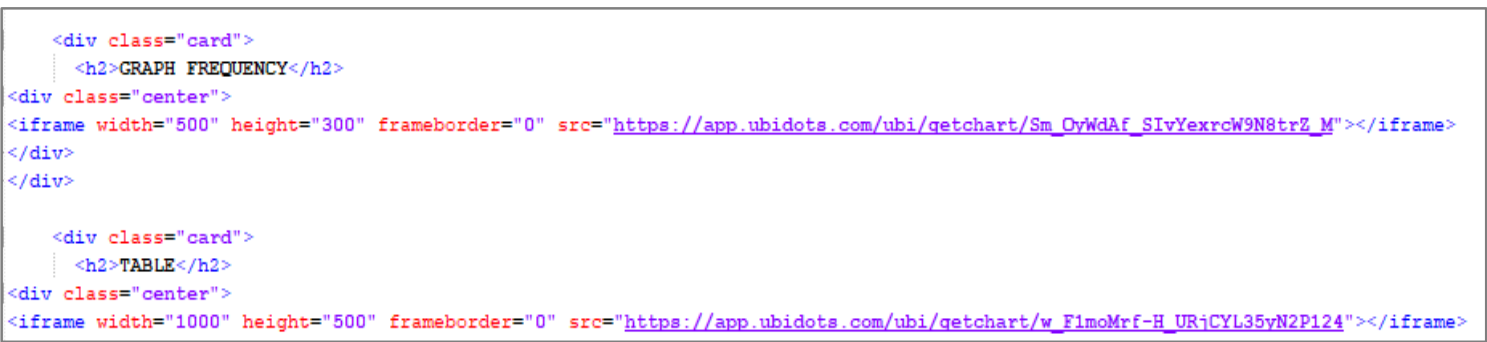

(b)

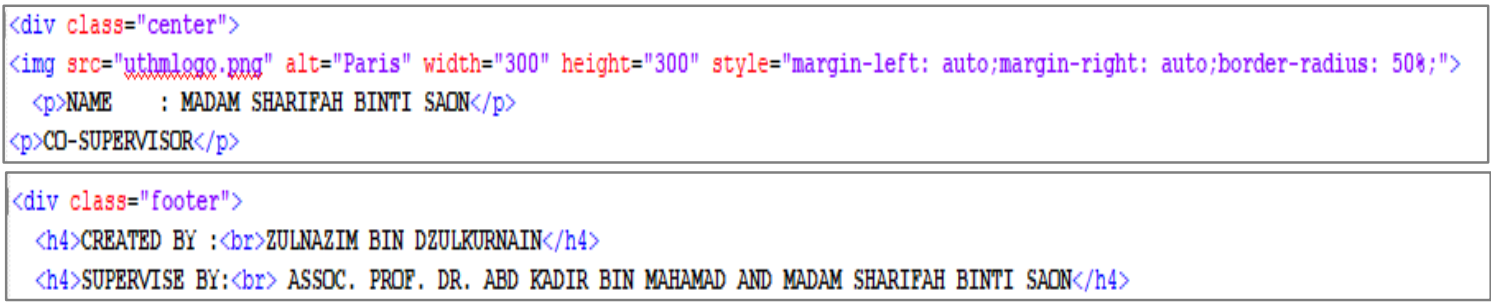

(c)

Figure 7. Coding of webpage development, (a) homepage.html, (b) datalog.html and (c) aboutwriter.html

Once compiled, the webpage was deployed by using "000webhost" and the public user can access the system. Admin are authorize and able to change the setting at the UBIDOT dashboard. The public URL for this webpage is "https://uthmparkingspot.000webhostapp.com/".

Figure 8 (a) shows the website that contain the real-time monitoring for the parking space. The number appear in the website was show the available parking space. When the data was send to UBIDOT cloud by the hardware, the website have been update the number/value automatically. Via this homepage, the user were able to go to the About Writer tab or Data Logging tab by clicking on the ABOUT WRITER or DATALOG button on the top of homepage. Figure 8 (b) and (c) show About Writer and Data Logging page. 


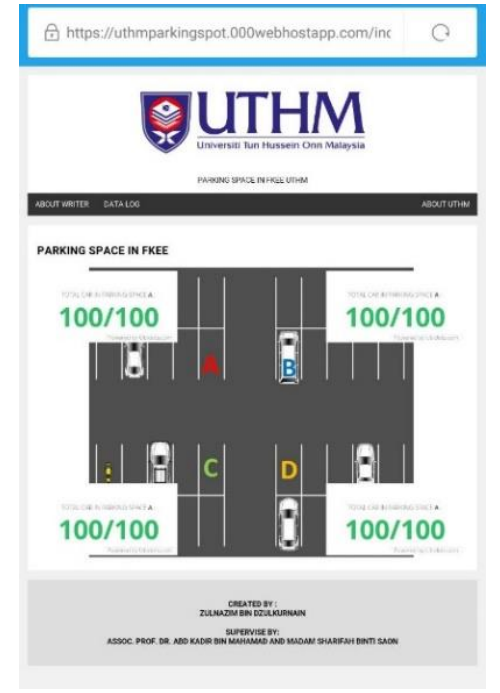

(a)

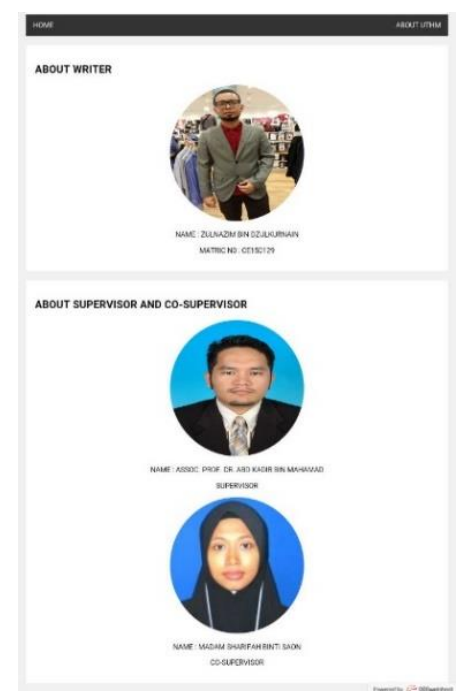

(b)

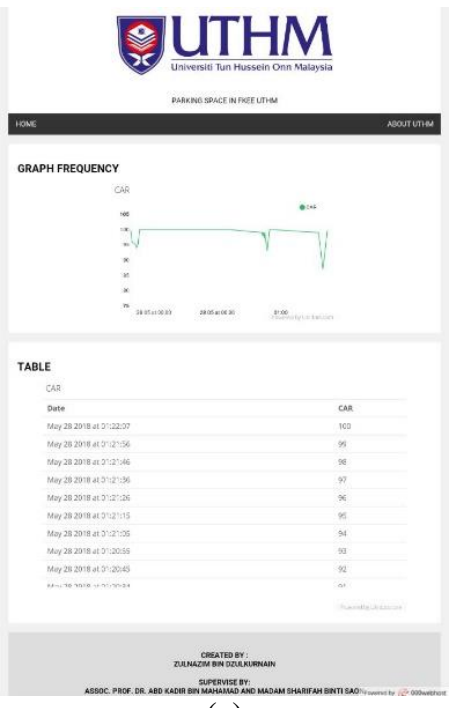

(c)

Figure 8. Webpage of the developed system, (a) Homepage, (b) About writer and (c) Datalog page

\subsection{System Performance}

The developed system was successfully tested at parking area, located at Block QB, UTHM. This process was conducted to test the system in term of accuracy and time management of parking flow. Figure 9 (a), (b) and (c) show the working processes of the developed system, which were able to update the information of available parking space into the website.

Figure 9 (a) shows the number of available parking space via the Parking Space tab view. Once the vehicle pass by the sensor as shown in Figure 9 (b), system automatically update the new information of available space. Updated information have been sent to the cloud platform, then been retrieved by system before have been update the total number of parking available into Parking Space tab as shown in Figure 9 (c).

Same working process was repeated for outgoing vehicle, as in Figure 10 (a) and (b). Once sensor detect the outgoing vehicle, the information update to the cloud platform and the Parking Space tab shows the latest information as in Figure 10 (b).

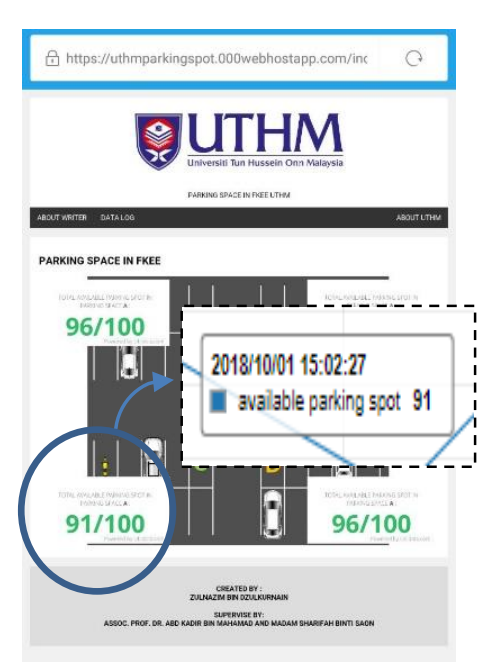

(a)

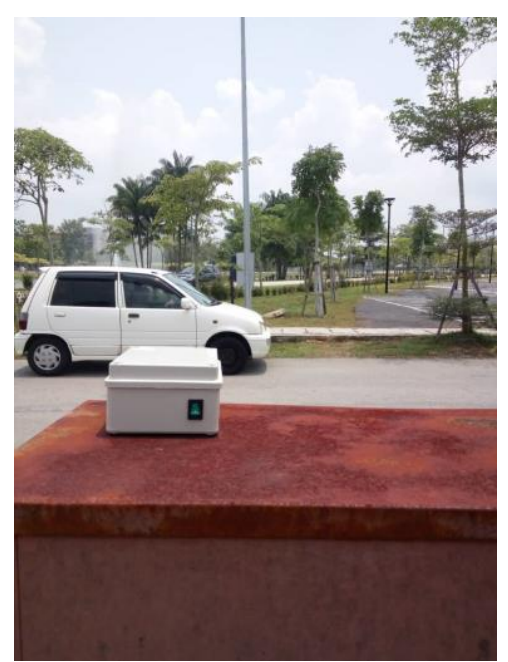

(b)

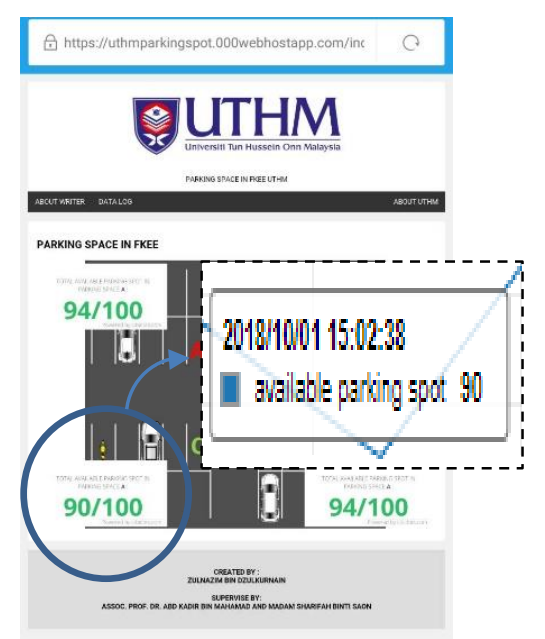

(c)

Figure 9. Working process of the developed system; (a) Parking Space tab view, (b) detected vehicle, and (c) updated information of parking availability 


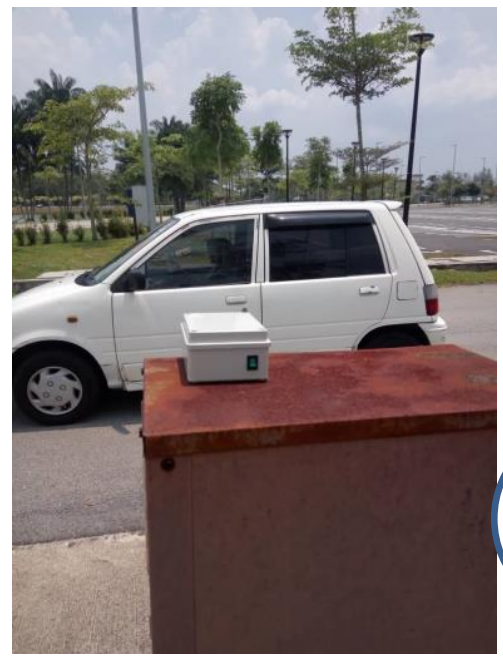

(a)

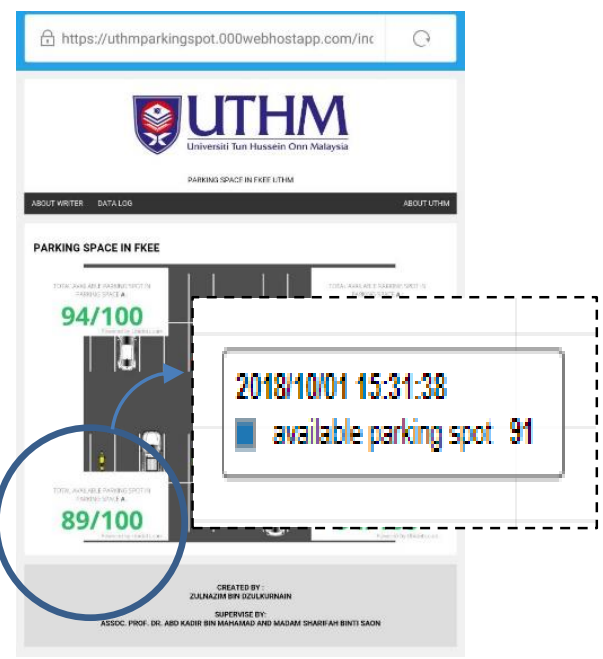

(b)

Figure 10. Working process of outgoing vehicle, (a) Outgoing vehicle from parking area, (b) Updated information of parking availability

This system was successfully developed and suitable to be implement for the per entry charge parking area. This system also able to estimate daily or monthly vehicle that enter the parking area. Thus, the owner of parking area is able to estimate their income per month or daily roughly. Figure 11 shows the system estimate for the vehicle during entering to the parking zone.

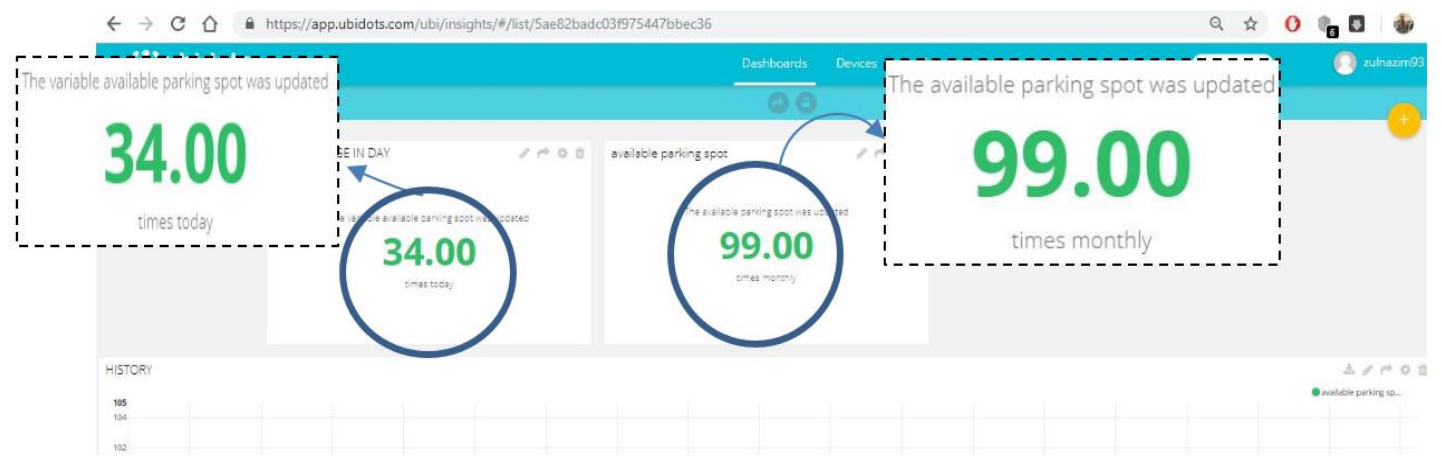

Figure 11. System estimate entering vehicle to the parking area

\section{CONCLUSION}

Traffic monitoring and routing system is very important today, thus, by implementing this project it can ease other people and provide practical system to find the available parking spot.

This project is the clear indication about traffic monitoring system for people who does not want to waste their time searching for an available parking space. It is also convenient to the owner of the system because the user are able to find the spot without hassle, in other words, this system expected to prevent traffic congestion and collision.

\section{ACKNOWLEDGEMENTS}

The financial support received from the TIER 1 RESEARCH GRANT: Vot U855, Office for Research, Innovation, Commercialization and Consultancy Management (ORICC), Universiti Tun Hussein Onn Malaysia is gratefully acknowledged. 


\section{REFERENCES}

[1] M.A. Salman, et al., "Traffic Delay Estimation With V2X Communication For An Isolated Intersection," International Conference on Engineering and Technology (ICET), pp. 1-6, 2017.

[2] P. Rizwan, S et al., "Real-time smart traffic management system for smart cities by using Internet of Things and big data," Int. Conf. Emerg. Technol. Trends. pp. 1-7, 2016.

[3] Koga, K. "Integrated Traffic Flow Monitoring System in a Large-scale Tunnel," Proceedings of Conference on Intelligent Transportation Systems. pp. 165-170, 1998.

[4] A. Yavari, et al., "Contextualised Service Delivery in the Internet of Things," IEEE $3^{\text {rd }}$ World Forum Internet Things. pp. 454-459, 2016.

[5] A. Zanella, et al., "Internet of Things for Smart Cities," IEEE Internet Things Journal, vol. 1(1), pp. 22-32, 2014.

[6] G. Singh, et al., "Smart Collision Avoidance and Hazard Routing Mechanism for Intelligent Transport Network," IOP Conference Series: Materials Science and Engineering, vol. 226 (1), 012107, 2017

[7] L. Sumi and V. Ranga, "Sensor enabled Internet of Things for smart cities," Fourth Int. Conf. Parallel, Distrib. Grid Comput, pp. 295-300, 2016.

[8] A. Sharif, "Internet of Things - Smart Traffic Management System for Smart Cities using Big Data Analytics," $14^{\text {th }}$ International Computer Conference on Wavelet Active Media Technology and Information Processing (ICCWAMTIP), pp. 281-284, 2017.

[9] S.M. Hatim, et al., "VANETs and Internet of Things (IoT): A Discussion," Indonesian Journal of Electrical Engineering and Computer Science, vol. 12(1), pp. 218-224, 2018.

[10] R.M. Patil, et al., "Application-based Smart Parking System using CAN bus," Indonesian Journal of Electrical Engineering and Computer Science, vol. 12(2), pp. 759-764, 2018.

[11] M.H.A. Wahab, et al., "GSM-based notification system and location tagging using GPS for smart recycle bin," International Journal of Machine Learning and Computing, vol. 8(5), pp. 495-500, 2018.

[12] A.R.A. Rudin, et al., "Occupancy monitoring system for campus sports facilities using the Internet of Things (IoT)," IEEE Conference on Wireless Sensors, ICWiSE, pp. 100-105, 2017.

\section{BIOGRAPHIES OF AUTHORS}

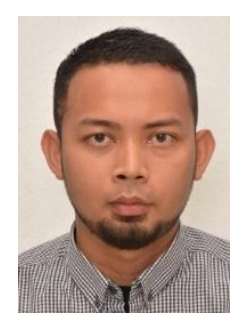

Zulnazim Dzulkurnain received his Diploma in Electronic Engineering (Communication) in 2014 from Politeknik Ungku Omar before pursuing Bachelor Degree in Electronic Engineering at Universiti Tun Hussein Onn Malaysia UTHM, 2019. During the period from Febuary until December 2018, he was research assistant for the grant project titled "Traffic Management \& Routing Solution CCTV with Analytical Tool.

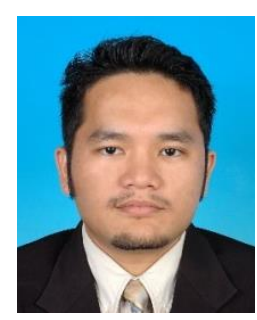

Abd Kadir Mahamad received his Bachelor of Science in Electrical Engineering (2002) and Master of Electrical Engineering (2005) from University Tun Hussein Onn Malaysia before pursuing Doctor of Philosophy (Computer Science and Electrical Engineering) at Kumamoto University, Japan (2010). He currently an Associate Professor at Faculty of Electrical and Electronic Engineering UTHM and registered as Professional Engineer. During the period of May 2015 through May 2016, he was doing industrial attachment at Melaka ICT Holdings Sdn Bhd, as Executive Assistant Manager and was involved in Smart City project in Melaka. He currently leads a research team in Video Analytic and Internet of Things. His research interests include Deep Learning, Smart City, Intelligent System applications and embedded system. He is also a Senior Member of IEEE, Institute of Engineering Malaysia (IEM) and Board of Engineering Malaysia (BEM).

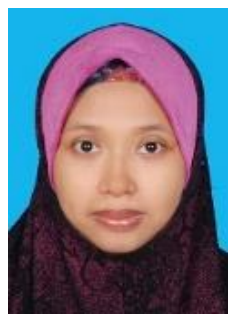

Sharifah Saon is currently a Senior Lecturer in the Faculty of Electrical and Electronic Engineering, Universiti Tun Hussein Onn Malaysia, Malaysia. He received the Bachelor of Science in Electrical Engineering and Master of Electrical Engineering from Universiti Teknologi Malaysia, and Kolej Universiti Tun Hussein Onn Malaysia, Malaysia, in 2001, and 2004, respectively. Her research interest is in the area of theoretical digital signal processing, visible light communication and digital \& data communication. Including the application to IoT and bigdata analysis. She is a Member of IEEE, Institute of Engineering Malaysia (IEM) and Board of Engineering Malaysia (BEM). 


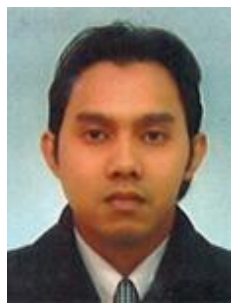

Mohd Anuaruddin Ahmadon graduated from Kumamoto National College of Technology, Japan, in 2012. He received his B.Eng. (2014), M.Eng. (2015) and Dr.Eng. (2017) from Yamaguchi University, Japan. He is currently an Assistant Professor at Graduate School of Sciences and Technology for Innovation, Yamaguchi University. He was awarded IEEE Consumer Electronics Society East-Japan Young Scientist Paper Award in 2016. His research interest includes software engineering, service engineering and its application to Internet of Things, multi-agent system and cyber-security. He is a member of IEEE and IEICE, Japan.

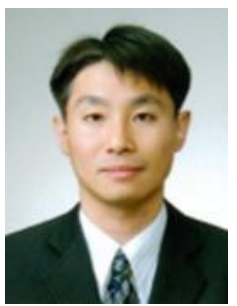

Shingo Yamaguchi is currently a (Full) Professor in the Graduate School of Sciences and Technology for Innovation, Yamaguchi University, Japan. He received the B.E., M.E. and D.E. degrees from Yamaguchi University, Japan, in 1992, 1994 and 2002, respectively. He was an Assistant Professor in the Faculty of Engineering, Yamaguchi University, from 1997 to 2007. He was also a Visiting Scholar in the Department of Computer Science at University of Illinois at Chicago, United States, in 2007. He was an Associate Professor in the Graduate School of Sciences and Technology for Innovation, Yamaguchi University, from 2007 to 2017. His research interest is in the area of theoretical computer science and software engineering, including their application to business process management, IoT, bigdata analysis, AI and cyber security. He is also a Senior Member of IEEE, Board of Governors of IEEE Consumer Electronics Society, Young Professionals Chair of IEEE Consumer Electronics Society, and a member of International Coordination Committee of ITC-CSCC. In academic societies other than IEEE and IEICE, he plays many important roles, which is an Editorial Board Member of International Journal of Internet of Things and Cyber-Assurance. 